\title{
ALMEIDA, Alfredo Wagner Berno de; MOURÃO, Laís. 2017. Questões agrárias no Maranhão contemporâneo
}

Carlos Alexandre B. Plínio dos Santos e Márcia Leila de Castro Pereira

\section{(2) OpenEdition}

Journals

Edição electrónica

URL: http://journals.openedition.org/aa/3568

DOI: $10.4000 / a a .3568$

ISSN: 2357-738X

Editora

Programa de Pós-Graduação em Antropologia Social (UnB)

Edição impressa

Data de publição: 1 junho 2019

Paginação: 365-370

ISSN: 0102-4302

Refêrencia eletrónica

Carlos Alexandre B. Plínio dos Santos e Márcia Leila de Castro Pereira, «ALMEIDA, Alfredo Wagner Berno de; MOURÃO, Laís. 2017. Questões agrárias no Maranhão contemporâneo», Anuário Antropológico [Online], v.44 n.1 | 2019, posto online no dia 06 julho 2019, consultado o 28 abril 2021. URL: http:// journals.openedition.org/aa/3568 ; DOl: https://doi.org/10.4000/aa.3568

\section{(c) $)(9)$}

Anuário Antropológico is licensed under a Creative Commons Atribuição-Uso Não-Comercial-Proibição de realização de Obras Derivadas 4.0 International. 


\title{
ALMEIDA, Alfredo Wagner Berno de; MOURÃO, Laís. 2017. Questões agrárias no Maranhão contemporâneo. Manaus: UEA. 124 pp.
}

\author{
Carlos Alexandre B. Plínio dos Santos \\ Universidade de Brasília - Brasil
}

Márcia Leila de Castro Pereira Universidade Federal do Piauí - Brasil

O livro Questões agrárias no Maranhão contemporâneo analisa as relações sociais camponesas impactadas por projetos desenvolvimentistas, no estado do Maranhão. Assim, ao contrário do que poderia parecer, o termo "contemporâneo", presente no título, contém a ideia crítica que os organizadores deste livro invocam; o exercício proposto procura romper a própria temporalidade e seus limites. A novidade desse termo, segundo os autores, "atém-se a processos históricos, reais, que não correspondem a "estágios" ou "etapas" fixas e determinadas, sendo necessariamente dinâmicos, contingentes" (: 41).

O livro tem como base reflexiva um relatório, escrito entre o final de 1974 e início de 1975, pelos antropólogos Alfredo Wagner Berno de Almeida e Laís Mourão, solicitado pela Secretaria de Planejamento (SEPLAN) do estado do Maranhão para auxiliar na construção do "Diagnóstico da economia do Maranhão", o qual iria subsidiar o Plano de Governo estadual de 1975-78. Naquele período, via-se com clareza a inserção do Maranhão no contexto discursivo da ideologia nacional-desenvolvimentista. Tais estudos, à época, eram indispensáveis para consolidar o processo de desenvolvimento, e, nesse sentido, era imperativo definir qual seria o setor da economia mais indicado para sustentar o avanço desse processo; e como os autores irão demonstrar, haverá o predomínio do setor primário. Entretanto, segundo Almeida, o relatório se manteve no plano das interpretações, ou seja, "que não são imediatamente aplicáveis para fins de um plano de governo ou um programa de medidas visando 'desenvolvimento', e por isso não foi utilizado pela SEPLAN” (: 55).

Em 1976, os autores publicaram o artigo Questões agrárias no Maranhão contemporâneo, resultado do esforço de pesquisa não utilizada pela SEPLAN, no periódico científico Pesquisa Antropológica, organizado pelos professores Júlio Cezar Melatti e Martín Alberto Ibáñez-Novion, do Departamento de Antropologia da Universi- 
dade de Brasília. Este texto, agora republicado no homônimo livro, completa 42 anos de existência.

O livro Questões agrárias no Maranhão contemporâneo possui três partes. A primeira parte apresenta um prólogo e uma nota. O "Prólogo: Variações no sistema repressor da força de trabalho e o porquê desta reedição" orienta o leitor e permite que Alfredo Wagner de Almeida forneça alguns detalhes sobre o processo de elaboração do livro. O autor explica que as discussões ali contidas foram suscitadas no contexto de uma palestra proferida no $8^{\circ}$ Congresso Estadual dos Trabalhadores Rurais Agricultores e Agricultoras Familiares do Estado do Maranhão, ocorrida em São Luís / MA, entre $1^{\circ}$ e 3 de junho de 2016. A referida palestra aconteceu na mesa redonda intitulada "Análise de conjuntura”, que examinou o contexto político atual (como o populismo judiciário e a judicialização da política; a reprimização da economia por meio do agronegócio; os direitos trabalhistas; e os direitos territoriais de indígenas e quilombolas). Tais questões fortaleceram sua “disposição e confirmaram o propósito de recolocar o texto Questões agrárias no Maranhão contemporâneo no debate político" (: 16).

Já a "Nota sobre o periódico Pesquisa Antropológica” é de autoria do antropólogo Júlio Cezar Melatti. Em seis páginas, esse autor faz um histórico sobre Pesquisa Antropológica, criado em 1975 e mantido até 1983. Em seus oito anos de existência foram publicados, além do texto Questões agrárias no Maranhão contemporâneo, resenhas de livros, notícias de projetos em andamento, resumos de dissertações defendidas, dissertações, artigos, entre outras matérias. O periódico teve uma existência bastante exitosa, além de uma circulação que transcendia em muito os objetivos propostos incialmente.

Na segunda parte do livro, o leitor encontrará um prefácio e o texto central, ao qual todo o restante se refere. O prefácio, "Repensando a Ação Antropológica: prefácio à edição de 2016”, assinado por Alfredo Wagner Berno de Almeida, circunstancia criteriosamente as condições de elaboração do texto central, Questões agrárias no Maranhão contemporâneo e suas respectivas implicações à época, oferecendo elementos para uma releitura desse documento no tempo presente, clarificando, assim, o programa em que convergem organizadores e autores do livro como um todo. Evidencia a antropologia da ação, antropologia em ação e antropologia aplicada formuladas, principalmente, por George McClelland Foster e Sol Tax, tornando visível a configuração de campos particulares de produção de conhecimentos e de práticas políticas, que nos ajuda a refletir sobre o trabalho do antropólogo, possibilidades de 
intervenção, tanto na época quanto na atualidade, no âmbito dos programas integrados a projetos de desenvolvimento do Estado.

Ainda nessa segunda parte do livro, está o texto central Questões agrárias no Maranhão contemporâneo, inicialmente publicado em 1976 e que agora também intitula o livro. Nessa reedição, os autores acrescentaram material jornalístico, análise estatística e documentos inéditos, todos da época. A divisão interna desse texto apresenta uma Introdução, "Análise do setor primário no planejamento estadual” e "As transformações na estrutura agrária”. Possui também um Anexo, "Sugestões para pesquisa em áreas urbanas", e, por último, as Referências bibliográficas.

Vale detalhar esse conteúdo, já que se trata do cerne analisado pelo livro. Na Introdução, Almeida e Mourão definem qual será a dinâmica analítica e delimitam os grupos sociais focalizados a partir de suas mútuas relações no processo produtivo. Tal ênfase se dá a partir de tipos de "unidades de produção" - "unidades de produção camponesas" e "unidades de produção capitalistas" -, e não segundo a extensão territorial que monopolizam e/ou trabalham e nem conforme as atividades que exercem. Por meio desses tipos, os autores construíram uma rica relação de categorias, demonstrando a grande heterogeneidade das interações e dos atores sociais no meio rural maranhense. Sublinha-se então que elegeram, como objeto de estudo, as relações sociais no meio rural maranhense. Assim, foi possível evidenciar os fatores institucionais e socioculturais que atuavam na composição e na dinâmica da estrutura socioeconômica peculiar do meio rural. Desse modo, as pesquisas no campesinato deveriam observar suas interações internas (com outros agricultores) e externas (com a cidade), como interações presentes numa rede de relações sociais.

Em “Análise do setor primário no planejamento estadual”, os autores fazem uma bem articulada análise do "setor primário" no planejamento estadual. Visto como a única alternativa para o Maranhão sair do subdesenvolvimento e acelerar sua economia, o denominado "setor primário" foi priorizado pelo Estado, apesar da opinião divergente do setor industrial. A estratégia de ação adotada, que tinha como base o setor primário, figurava como atividade líder projetada para ganhar expressiva dimensão econômica, política e social. A opção foi feita em favor do setor primário, com base no argumento de que o desenvolvimento acontece em estágios e que o crescimento desse setor marcaria esse primeiro momento. Sua modernização, segundo a lógica economicista governamental, passava pela introdução no meio rural dos projetos agropecuários. Neste sentido, terras seriam disponibilizadas para esses projetos, os quais tinham a pretensão de absorver as famílias camponesas 
vindas das áreas de “tensão social” do Estado.

Ao desconstruírem a noção de "setor primário", os autores perceberam que esse se relacionava, "enquanto atividade, à pecuária, enquanto modalidade de exploração, à grande empresa agropecuária com mão de obra assalariada” (: 77). Além disto, "setor primário" também era entendido “como introdução na área rural de projetos agropecuários” (: 78), que teriam grandes incentivos fiscais da Superintendência do Desenvolvimento da Amazônia (SUDAM) e da Superintendência de Desenvolvimento do Nordeste (SUDENE). Destarte, terras devolutas, vistas pelo Estado como áreas “desocupadas”, seriam disponibilizadas para os projetos agropecuários. Entretanto, como essas áreas não estavam desabitadas, pois nessas terras, além de já haver unidades de produção camponesas, existiam também territórios indígenas, o que intensificaria os conflitos pela posse e propriedade da terra.

Em "As transformações na estrutura agrária”, com base numa análise histórica sobre a economia agrária maranhense, em um contexto de crescente importância que se deu ao setor primário, Almeida e Mourão demonstram os conflitos sociais em torno da terra gerados pelo latifúndio tradicional, que teve como consequência a expropriação do campesinato. Segundo os autores, separar o camponês "do meio de produção, terra, tende a desorganizar o sistema produtivo, agricultura e extrativismo, mantenedor do abastecimento das áreas urbanas” (: 119). Esta ação expropriatória é explicada "pela transformação da pecuária extensiva, tradicional, que coexistia com a economia camponesa, e agora lhe é antagônica e pela implantação dos grandes projetos agropecuários em áreas próximas ou de ocupação camponesa" (: 119-120).

O aumento das áreas de pastagem do grande latifúndio e a separação do meio de produção camponesa, a terra, segundo os autores, reverberaram nos centros urbanos, pois desorganizou o sistema produtivo mantenedor do abastecimento das áreas urbanas maranhenses. Além disso, como os projetos agropecuários empregavam pouca mão de obra, a migração, para as periferias das cidades, era a única alternativa para vários camponeses.

Como afirmado por Klass Woortmann (1990), a terra não é simples coisa ou mercadoria. Porém, a tendência economicista vê o campesinato como resultado de determinações impostas pela lógica do capital. De acordo com Michael Taussig (1983), se o mercado domina o campesinato, ele não o organiza. Na contramão dessas análises, estão os planos desenvolvimentistas governamentais autoritários que ainda insistem em modelos econômicos inexequíveis para o universo rural. 
No final desse texto central, Almeida e Mourão, ao analisarem o mercado de produção e comercialização do arroz produzido por camponeses no Maranhão e o mercado de carne bovina, afirmam que o primeiro, por causa das flutuações de mercado, apresenta grandes vantagens sobre o segundo. Além disso, a produção de arroz, combinada com a produção de amêndoa de babaçu e de farinha de mandioca, põe em evidência a força produtiva das unidades familiares na economia regional. Por isso, sugerem que sejam repensadas as abordagens sobre as questões que envolvem a expropriação dos camponeses no Estado do Maranhão.

O livro termina com a terceira e última parte, em que encontramos "Uma leitura obrigatória: à guisa de posfácio”, de Helciane de Fátima Abreu Araújo. Nela, a autora evidencia, dentre outros, dois aspectos importantes do texto Questões agrárias no Maranhão contemporâneo: a "presencialidade" das análises e a reflexão crítica que ele provoca.

Podemos afirmar que em virtude dos projetos desenvolvimentistas do passado, houve um aumento da concentração fundiária, os problemas ambientais se multiplicaram e intensificaram-se as desigualdades sociais tanto no campo como nas cidades. Questões agrárias no Maranhão contemporâneo é, sem dúvida, um livro que contribui enormemente para pensar as transformações que ocorreram e que ocorrem no meio rural maranhense. Finalmente, não se trata, portanto, como afirmado por Almeida, de uma reedição "serôdia", pois esse livro nos faz pensar nas atuais resistências ao reconhecimento de formas diversas de organização social e cultural. Principalmente, as tentativas de suprimir os direitos fundamentais das sociedades camponesas e dos povos e comunidades tradicionais, de setores historicamente alinhados com lógicas de dominação colonial, que agem a partir de lugares privilegiados do cenário político brasileiro.

Recebido: 17/07/2018

Aprovado: 13/09/2019 
Carlos Alexandre B. Plínio dos Santos é é professor Adjunto do Departamento de Antropologia (DAN) da Universidade de Brasília (UnB). Realizou estágio Pós-Doutoral (bolsa Capes) no Programa de Pós-Graduação em Antropologia Social (PPGAS) DAN/UnB (2012 a 2015). Finalizou estágio Pós-Doutoral Júnior (bolsa CNPq) pelo Instituto de Estudos Comparados em Administração Institucional de Conflitos/InEAC, vinculado a Universidade Federal Fluminense (2011). No PPGAS/DAN/UnB concluiu o Doutorado (2010) e o Mestrado em Antropologia Social (2006). Ainda no DAN/UnB, realizou o Bacharelado em Ciências Sociais, habilitação em Antropologia (1995). Possui também graduação em Geografia (1990), graduação em Estudos Sociais (1989) e especialização em Geografia do Brasil (1990). Linha de pesquisa: Campesinato, Parentesco, Memória, Escravidão e pós-emancipação, Comunidades Negras Rurais e Urbanas - Quilombolas. ORCID: 0000-0002-0606-4342. Contato: carlosalexandrebps@gmail.com

Márcia Leila de Castro Pereira possui Graduação em Sociologia e Antropologia (2002), Mestrado e Doutorado em Antropologia Social pela Universidade de Brasília (2009), atuando nos temas Etnologia Indígena, Territorialidades, poder e conflitos socioambientais no contexto de grandes empreendimentos, definições fundiárias e demandas por direitos de povos tradicionais. Atualmente é docente do Departamento de Ciências Sociais/ / UFPI, professora permanente do Programa de Mestrado em Antropologia e professora colaboradora do Programa Regional de Pós-Graduação em Desenvolvimento e Meio Ambiente (PRODEMA) do Núcleo de Referência em Ciências Ambientais do Trópico Ecotonal do Nordeste (TROPEN). ORCID: ORCID no 0000-0002-4531-5001.Contato: marcialeila23@gmail.com

\section{Referências bibliográficas}

TAUSSIG, MichaelT. The Devil and Commodity Fetishism in South America. Chapel Hill:The University of North Carolina Press, 1983.

WOORTMANN, Klass. “Com parente não se neguceia”. Anuário Antropológico, v. 87. Brasília: Editora Universidade de Brasília; Rio de Janeiro: Edições Tempo Brasileiro. 1990. 